\title{
Fibreoptic intubation in airway management: a review article
}

\author{
Jolin Wong ${ }^{1}$, MBBS, FAnZCA, John Song En $\underline{L e}^{1}$, MBBS, MMed, Theodore Gar Ling Wong ${ }^{1}$, MD, FRCPC,
} Rehana lqbal${ }^{2}$, MBBS, FRCA, Patrick Wong ${ }^{1}$, MBBS, FRCA

Since the first use of the flexible fibreoptic bronchoscope, a plethora of new airway equipment has become available. It is essential for clinicians to understand the role and limitations of the available equipment to make appropriate choices. The recent 4th National Audit Project conducted in the United Kingdom found that poor judgement with inappropriate choice of equipment was a contributory factor in airway morbidity and mortality. Given the many modern airway adjuncts that are available, we aimed to define the role of flexible fibreoptic intubation in decision-making and management of anticipated and unanticipated difficult airways. We also reviewed the recent literature regarding the role of flexible fibreoptic intubation in specific patient groups who may present with difficult intubation, and concluded that the flexible fibrescope maintains its important role in difficult airway management.

Keywords: airway obstruction, anaesthetic techniques, fibreoptic intubation, neuromuscular blocking

\section{INTRODUCTION}

Airway management has progressed since the first orotracheal intubation in 1878 using a blind digital technique.(1) Since the 1940s, the Macintosh laryngoscope has allowed tracheal intubation under direct vision. More recently, indirect laryngoscopy has revolutionised difficult airway management with its ability to 'look around the corner' during intubation, obviating the need for alignment of the oral, pharyngeal and laryngeal axes. ${ }^{(2)}$

The intubating fibreoptic bronchoscope (FOB) was first described in 1967 by Peter Murphy ${ }^{(3)}$ and has a quoted success rate of $88 \%-100 \% .{ }^{(4)}$ Some authors still consider it to be the gold standard in anticipated difficult airway management. ${ }^{(5)}$ The introduction of newer equipment, such as supraglottic airway devices, and indirect laryngoscopy has dramatically changed airway management and resulted in a decline in the use of fibreoptic intubation (FOI). ${ }^{(6)}$ Yet, in spite of advances in these airway devices, lapses in airway assessment and strategic planning still persist, leading to devastating consequences. Analysis of these adverse airway events led the 4th National Audit Project (NAP4) of The Royal College of Anaesthetists, United Kingdom $(U K)$, to conclude that poor judgement, inappropriate choice of equipment, poor education and inadequate training are contributory factors in major airway complications. ${ }^{(7)}$ It is therefore imperative that $\mathrm{FOI}$ is considered in a clinical context as part of a complete airway strategy.

This narrative review summarised the indications, contraindications, complications and challenges in FOI use. Subsequently, we evaluated the role of FOI as an invaluable primary or backup modality in airway management, followed by a discussion on the role of FOI in anticipated difficult airway management in specific patient groups, including obese and pregnant patients as well as those who have suffered major trauma. The practical aspects and training (including ethico-legal concerns) in FOI are reviewed and discussed elsewhere. ${ }^{(8)}$

\section{METHODS}

We conducted a literature search on PubMed from 1996 to 2016 using the phrase 'fibreoptic intubation'. Publications in English were included at the authors' discretion if they were relevant to FOI. These included articles related to the indications and contraindications, complications and the use of FOI in airway management. Review articles, case reports/series and clinical trials were included. Publications unrelated to fibreoptic-guided endotracheal intubation were excluded. Additional articles were manually searched from the references of retrieved articles.

\section{USES AND COMPLICATIONS Indications and contraindications}

From Murphy's initial use of FOI as an alternative to blind nasal intubation, ${ }^{(3)}$ the use of the $\mathrm{FOB}$ has expanded considerably. Boxes 1 and 2 show the indications and contraindications of the use of the FOB.

\section{Morbidity and mortality}

Despite being the gold standard, FOI is still associated with significant morbidity. The NAP4 had two reported cases of failed awake FOI that were converted to general anaesthesia (one as a result of profuse bleeding) and required surgical airways due to obstruction and regurgitation. ${ }^{(7)}$

\section{Airway complications}

The most common complications were associated with the airway: sore throat $(9.5 \%-35 \%) ;^{(9,10)}$ hoarse voice $(4 \%-5 \%) ;^{(9,11)}$ erythema and haematoma of the vocal cords $(6.2 \%$ and $3.8 \%$, respectively); ${ }^{(9,11)}$ epistaxis $(1.3 \%-10 \%) ;(10,12)$ and influenza-like 
Box 1. Indications and uses of the flexible fibreoptic bronchoscope:

1. Special patient groups

- Difficult airway management:

- Anticipated difficult airways (based on predictive airway tests, history of difficult or failed intubation and patient characteristics, e.g. obstetrics and morbidly obese)

- Unanticipated difficult airways: primary or secondary 'rescue' techniques for tracheal intubation

- Diagnostic information (akin to flexible nasendoscopy) before deciding on subsequent airway management plan

- Poor dentition or with teeth at risk of damage if conventional laryngoscopy is performed

- High risk of aspiration (awake technique)

- Unstable cervical spine or vertebrobasilar artery insufficiency: allow repeat neurological assessment after intubation and operative positioning before induction of general anaesthesia

2. Confirmation of position of airway devices

- Endotracheal tube depth

- Tracheostomy insertion and positioning

- Double lumen tube and bronchial blocker placement and depth assessment

3. Training purposes

- Hands-on training for trainees on manikins/cadavers

- Hands-on training in patients with normal airways under general anaesthesia



- Raised pressure (intracranial, intraocular) that may be exacerbated by coughing

- Trauma (basilar skull fractures)

- Coagulopathy (risk of epistaxis during nasal fibreoptic intubation)

- Allergy to local anaesthetics

- Refusal or uncooperative patient

2. Clinician factors

- Lack of skill

symptoms $(4 \%) .{ }^{(10)}$ When awake nasal FOI (i.e. no muscle relaxants) was compared to asleep conventional intubation by direct laryngoscopy using rocuronium, Heidegger et al found no statistical difference in the incidence of vocal cord sequelae (8.5\% and $9.3 \%$, respectively). ${ }^{(11)}$ However, their study used different tracheal tubes (flexible silicone vs. polyvinyl chloride). Tracheal perforation, resulting in subcutaneous emphysema and pneumomediastinum, has also been reported. ${ }^{(13)}$

\section{Cardiovascular responses}

Awake FOl avoids the stimulation of oropharyngeal structures associated with direct laryngoscopy, but hypertension and tachycardia were commonly observed during insertion of the FOB through the vocal cords. ${ }^{(9)}$ The cardiovascular responses depend on the FOI technique. Hawkyard et al's study showed milder changes in mean arterial pressure changes and heart rate with awake nasal FOI (fall of $9 \mathrm{mmHg}$ and rise of 3 beats per minute $[\mathrm{bpm}]$, respectively) than with asleep orotracheal intubation using direct laryngoscopy (rise of $35 \mathrm{mmHg}$ and 24 bpm, respectively). ${ }^{(14)}$ When Xue et al compared nasal FOI with direct laryngoscopy for asleep nasal tracheal intubation, they found that nasal FOI was associated with significantly higher mean systolic blood pressure $(126.9 \pm 21.6 \mathrm{mmHg}$ vs. $108.8 \pm$ $11.1 \mathrm{mmHg}$, respectively) and heart rate $(100.5 \pm 16.4 \mathrm{bpm}$ vs. $87.6 \pm 17.9 \mathrm{bpm}$, respectively) compared with baseline values (similar for both groups). ${ }^{(15)}$ The higher systolic blood pressure and heart rate occurred despite avoidance of direct stimulation of the tongue base during nasal FOI, thereby minimising gagging and its associated pressor response. The patients had no airway topicalisation. The cardiovascular responses during FOI were attributed to prolonged intubation times (the resulting hypercarbia causes a rise in blood pressure and heart rate, but the authors considered this a minor contributory factor), FOI stimulation of the oropharyngeal structures, and jaw thrust. ${ }^{(15)}$

\section{Gastric complications}

Gastric complications included aspiration of gastric contents, ${ }^{(16)}$ although awake FOI was safely used in a case series of 123 patients at high risk of aspiration (with one case of haematemesis, but no patients developed signs of aspiration). ${ }^{(17)}$ Gastric rupture has been described in two cases when FOI was supplemented with oxygen insufflation down the working channel at flow rates of 3-5 L/min. ${ }^{(18,19)}$ As such, oxygen insufflation in this manner is not recommended due to the risk of barotrauma (secondary to a lack of an adequate expiratory pathway, e.g. narrow airway or laryngospasm) or gastric inflation/rupture (due to inadvertent entry into the oesophagus). ${ }^{(20)}$ Instead, high-flow nasopharyngeal oxygen insufflation is recommended. ${ }^{(21)}$

\section{Drug-related complications}

Complications can occur secondary to the drugs used for preparing the airway, including both sedatives and local anaesthetics. The NAP4 identified oversedation as a "significant problem area leading to failed FOI" and stated that it "increases the likelihood of airway obstruction". (7) Up to $14.3 \%$ of patients undergoing awake FOI experience hypoxia $\left(\mathrm{SpO}_{2}<90 \%\right)^{(22)}$ Lignocaine is the most commonly used local anaesthetic for airway topicalisation. The maximum dose of topical lignocaine is $8.2 \mathrm{mg} / \mathrm{kg}$ as recommended by the British Thoracic Guidelines, with systemic toxic effects generally occurring above $5 \mathrm{mcg} / \mathrm{mL}$. ${ }^{(23)}$ However, these effects have been reported in two volunteers undergoing awake FOI at lignocaine plasma concentrations below $3 \mathrm{mcg} / \mathrm{mL}{ }^{(24)}$ We recommend using the lowest possible dose to 
facilitate awake intubation, while maintaining vigilant monitoring for symptoms of lignocaine toxicity. ${ }^{(23)}$

\section{AIRWAY MANAGEMENT FOB in failed intubation guidelines}

The updated 2015 Difficult Airway Society (DAS) difficult intubation guidelines provide a strategy to manage the unanticipated difficult airway. ${ }^{(21)}$ The emphasis of Plan ABC has changed to 'face mask ventilation and intubation, maintain oxygenation and supraglottic airway devices insertion, and face mask ventilation'.(25) In these guidelines, FOI via a supraglottic airway device remains as an option in Plan B after failed initial intubation.

The American Society of Anesthesiologists (ASA) difficult airway algorithm caters for both anticipated and unanticipated difficult airways. ${ }^{(4)}$ The final airway strategy (Plan ABC) is dependent on the clinical merits and feasibility of four basic management choices, ${ }^{(4)}$ namely, whether to: keep the patient awake (e.g. awake FOI) or asleep; preserve or ablate spontaneous ventilation; use noninvasive or invasive airway devices; and use direct or indirect laryngoscopy (e.g. FOB) to facilitate tracheal intubation.

\section{Awake and asleep techniques}

Difficult airways exist in $5.8 \%$ of the population,(26) but most can be managed by conventional means (including the use of a bougie). High-risk patients should have their airway secured before induction of anaesthesia (i.e. awake intubation) to avoid potential morbidity and mortality associated with difficult or failed face mask ventilation, or difficult, repeated or failed attempts at tracheal intubation. ${ }^{(7,27)}$ Awake FOI and awake tracheostomy are the most common methods depending on the site and nature of the lesion. ${ }^{(28)}$ Performing FOI in asleep patients, in the presence of indicators that awake FOI would have been preferred, can lead to serious morbidity, including 'cannot intubate, cannot oxygenate' scenarios necessitating emergency surgical airways, and death. ${ }^{(7)}$ 18 such cases were reported in the NAP4. The advantages and disadvantages of awake FOI are listed in Box 3.

Unanticipated difficult airways may occur due to the poor predictive value of airway tests or failure of adequate assessment. ${ }^{(7)}$ Again, most cases can be managed with standard equipment and techniques. However, the need to create an air space and the complexity of obtaining or setting up the FOB may limit the use of FOI in such cases. In the 2015 DAS guidelines, after an initial failed Plan A intubation by laryngoscopy, Plan B is 'maintaining oxygenation: supraglottic airway device insertion' with subsequent consideration of various options, including intubating via the supraglottic airway device. ${ }^{(21)}$ This allows ventilation and creation of an air space for FOI. The latter technique is also termed low-skill FOI. ${ }^{(29)}$

Difficult airway algorithms from various countries differ considerably in their Plan ABC approaches. ${ }^{(30)}$ Cook et al showed that even with one specific difficult airway scenario (large retrosternal goitre), nine international airway experts had conflicting intubation strategies, including whether to use FOI as Plan A. ${ }^{(31)}$ Ultimately, decisions should be based on good
Box 3. Advantages and disadvantages of awake and asleep fibreoptic intubation:

Awake fibreoptic intubation

Advantages

- Airway muscle tone and spontaneous ventilation (and hence oxygenation) are maintained:

- Allows consideration of alternatives if technique fails

- Secretions may be swallowed, allowing a better view

- Presence of air bubbles (exiting a distorted or unrecognisable glottis) may help direct the endoscopist to the glottic opening

- May be performed either in a sitting (easier in an awake, cooperative patient) or supine position

- Sitting position (operator standing in front and face-to-face with the patient):

(a) More pleasant for the patient

(b) Accommodates patients who are unable to lie flat (e.g. those with severe rheumatoid arthritis, ankylosing spondylosis, wearing a halo traction device, or dyspnoea on lying flat secondary to cardiorespiratory disease)

(c) Effects of gravity may be beneficial (more patent airway, better respiratory function, decreased risk of gastric aspiration)

- Supine position (operator behind the patient): operator and fibreoptic bronchoscope are in line with airway

- Neurological assessment after intubation and positioning of the patient.

\section{Disadvantages}

- Patient distress: railroading of nasal tubes can be uncomfortable

- Operator may be less confident and skilful, as procedure is performed infrequently

Asleep fibreoptic intubation

Advantages

- Patient comfort

- For operator:

- Easy to change to other airway devices if necessary

- Cooperative patient

Disadvantages

- Benefits of being awake are lost

- Intubation is made more difficult due to airway collapse (secondary to loss of airway tone and supine positioning)

- Respiratory function is depressed, with reduced functional capacity and oxygen reserves

clinical judgement and experience in dealing with such cases. A multidisciplinary discussion is often warranted.

\section{Awake intubation with spontaneous ventilation}

The NAP4 recommended that anaesthetists "need to decrease our threshold for considering awake FOI as a first choice for difficult airway management" and that "when patient factors make FOI the preferred option in patients... consideration should first be made to performing it awake. The airway strategy should accept it may fail, particularly when performed in an unconscious patient".(7)

Awake FOI may be performed using airway topicalisation and/or sedation. Awake FOI with spontaneous ventilation and 
airway topicalisation alone allows the maintenance of airway muscle tone (Box 3). This is typically reserved for patients who have potentially difficult airways with respiratory compromise. Although airway topicalisation may be the most prudent way of preparing the airway for awake FOI, there have been case reports of secondary acute loss of airway due to decreased muscle tone or laryngospasm. ${ }^{(32-34)}$ In cases of upper airway obstruction, mild cases may be managed by awake FOI in skilled hands. ${ }^{(35,36)}$ However, in severe cases, awake FOI is contraindicated (see Page 116, 'Acute airway obstruction'). ${ }^{(37)}$

The addition of sedation allows for a more cooperative patient. Options include small intravenous boluses of opioids or benzodiazepines, and intravenous infusions of sedatives using total intravenous anaesthesia or target-controlled infusions. ${ }^{(38)}$ There are advantages and disadvantages to common sedatives used in awake FOI: propofol (good amnesic vs. poor antitussive and greater sedative effects); remifentanil (good analgesic and antitussive vs. poor amnesic effects); and dexmedetomidine (cardiovascular stability, preserves airway patency and avoids respiratory depression vs. poor intubating conditions and slower recovery). ${ }^{(38)}$ The difficulty with sedation is in achieving an appropriate level of sedation without compromising the airway. ${ }^{(38)}$

\section{Asleep intubation with spontaneous ventilation}

Asleep FOI while maintaining spontaneous ventilation typically involves an inhaled volatile induction, although titrated intravenous anaesthetic is possible. ${ }^{(39)}$ Maintaining bridges is achieved in two ways. Firstly, by ensuring a deep enough level of anaesthesia to allow airway examination and instrumentation, the risk of laryngospasm is minimised. Secondly, when using volatiles, there is cessation of drug delivery if spontaneous ventilation is lost or complete airway obstruction occurs. This theoretically allows the patient to 'lighten up' and regain airway muscle tone and/ or spontaneous ventilation. However, there are case reports of failure of this exit strategy. ${ }^{(7)}$ The advantages and disadvantages of asleep and awake FOI are listed in Box 3.

During asleep FOI, spontaneous ventilation can be augmented by pressure support using an endoscopy mask. Bourgain et al studied asleep FOI using this method in 32 ear, nose and throat cancer patients with anticipated difficult airways. ${ }^{(39)}$ Patients with pressure support of $10 \mathrm{~cm} \mathrm{H}_{2} \mathrm{O}$ had lower end-tidal carbon dioxide and larger tidal volumes than in spontaneously breathing patients $(38.1 \pm 4.2 \mathrm{mmHg}$ vs. $42.3 \pm 4.7 \mathrm{mmHg}$ and $371 \pm$ $139 \mathrm{~mL}$ vs. $165 \pm 98 \mathrm{~mL}$, respectively).

\section{Asleep intubation and use of muscle relaxants}

Asleep FOI can be performed after the administration of neuromuscular blocking drugs. However, a dilemma exists if there is an inability to ventilate by face mask even prior to administration of neuromuscular blockers: should one wake the patient up or give neuromuscular blockers to potentially facilitate face mask ventilation, risking the possibility of a 'cannot intubate, cannot oxygenate' scenario? One option to maintain bridges is to use short-acting drugs (e.g. succinylcholine) or easily reversible ones (e.g. rocuronium with pre-made sugammadex reversal agent). ${ }^{(40)}$ The likelihood of a successful exit strategy must be weighed when using suxamethonium or sugammadex. Careful patient selection is essential, and there should be a low threshold for awake intubation in patients who run the risk of difficult/impossible face mask ventilation or failed oxygenation.

In cases of unanticipated difficult or failed intubation when (immediately irreversible) intermediate or long-acting muscle relaxants have been used, the use of the FOB is dependent on its availability and on whether ventilation can be maintained. In an emergency, obtaining and preparing the FOB is more labourintensive and time-consuming than for videolaryngoscopy (VL) devices; hence, $\mathrm{VL}$ is more likely to be chosen than the FOB (90\% vs. $4 \%$, respectively). ${ }^{(41)}$ An alternative is to employ the use of low-skill FOI.

\section{Flexible fibreoptic endoscopy vs. indirect laryngoscopy devices}

In $\mathrm{VL}$ devices, cameras are recessed proximal to the tip ('leading

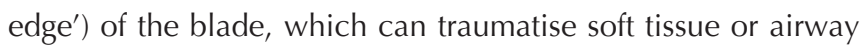
tumours before the operator can see and avoid them. ${ }^{(42)}$ In contrast, optical stylets (flexible FOB and rigid devices, e.g. Bonfils fibrescope) have their field of view at their tips. The rigid optical stylet, however, has a number of distinct advantages over the flexible FOB for orotracheal intubations. It is operated with one hand, leaving the other hand to create oropharyngeal space to optimise glottic view. The endotracheal tube (ETT) is preloaded with its distal tip slightly overhanging the tip of the rigid scope, partially protecting the tip from obstructed views and allowing easier and directed railroading of the ETT. The stylet and ETT can function as a solid unit to bypass (or even gently push aside) tumours, thereby avoiding shearing that may lead to distal airway obstruction.

Tracheal intubation may be performed with the FOB or VL devices in an anaesthetised or awake patient. Decision-making is based on previously described principles of airway management. Asleep VL, as an initial approach for intubation, was added as a fourth basic management choice in the revised ASA difficult airway algorithm. ${ }^{(4)}$ However, cases of awake VL have recently been described. ${ }^{(43-47)}$ The advantages of $\mathrm{VL}$ devices over the flexible FOB (Box 4) are likely to contribute to their future increased use in airway management. ${ }^{(2)}$

Comparative studies between awake FOI and awake direct laryngoscopy have favoured the use of $\mathrm{VL}$ devices in the management of difficult airways. Silverton et al compared the use of the GlideScope ${ }^{\circledR}$ (Verathon, Bothell, WA, USA) against the $\mathrm{FOB}$ for awake intubation in healthy volunteers. ${ }^{(46)}$ The GlideScope had fewer Cormack-Lehane Grade I and II ${ }^{(48)}$ results than the FOB (95.6\% vs. $100 \%$, respectively), but shorter median intubation times (16 seconds vs. 51 seconds, respectively). Rosenstock et al found that in anticipated difficult airways, there were no statistical differences in awake orotracheal intubation performed by experienced anaesthetists whether the FOB or the McGrath ${ }^{\circledR}$ VL device (Aircraft Medical, Edinburgh, Scotland, UK) was used. ${ }^{(45)}$ Kramer et al investigated awake nasal intubation in the supine position in 100 patients with anticipated 
Box 4. Advantages and disadvantages of awake intubation using videolaryngoscopy (VL) vs. awake fibreoptic intubation (FOI): Advantages

- For operator:

- Familiarity (most similar to the Macintosh laryngoscope blade)

- Perceived to be an easier (i.e. supraglottic) technique as it is less invasive

- Less steep learning curve

- Device and technique:

- Quicker setup time

- Devices are cheaper, portable and more robust

- Disposable blades are standard for some devices

- VL blades help create space during laryngoscopy and may offer an improved glottic view

- Overall success rate of VL devices is $94 \%-100 \%$ in unselected patients, comparable with direct laryngoscopy devices

- Growing evidence of use in special patient groups

- Rescue intubation following failed attempts using direct laryngoscopy

- Shorter intubation times

- Patient factors:

- Good patient acceptance

Disadvantages

- For patient

- Gag reflex may be difficult to suppress (whereas nasal FOI bypasses the back of the tongue)

- Associated with oropharyngeal trauma, e.g. palatopharyngeal arch perforation

- Device and technique:

- A good, or improved, glottis view using a VL device does not necessarily lead to easy intubation and may require the use of intubating adjuncts (e.g. bougie, stylet or fibreoptic bronchoscope) to guide tracheal tube placement

- Unable to enter and inspect the nasal cavity for nasotracheal intubation (although it may assist in the latter after oral placement)

- Devices are relatively bulky and lack manoeuvrability making them unsuitable for patients with severe trismus or space-occupying lesions in the oropharynx

difficult airways, comparing the C-MAC $®$ VL device (Karl Storz, Tuttlingen, Germany) with a standard FOB. ${ }^{(43)}$ Both techniques achieved a $96 \%$ success rate for intubation, but the C-MAC group had significantly shorter median intubation times (38 seconds vs. 94 seconds). Xue et al studied the combined use of the GlideScope and FOB (one operator manipulating one device each) to perform awake FOI in 13 patients, some of whom had predictors of difficult airway, and all cases were successful on the first attempt. ${ }^{(47)}$ The GlideScope was used to clear the airway and guide the FOB, and therefore helped to diagnose and resolve any tracheal tube impingement during advancement. A recent study compared awake nasotracheal intubation using FOI and the Trachway ${ }^{\circledR}$ in patients with limited mouth opening. Intubation using the Trachway, a video intubating stylet, was quicker and easier than using the FOB, with a mean intubation time of 35.4 seconds versus
71.8 seconds and an intubation difficulty score of 'no difficulty' for $100 \%$ versus $55 \%$ of patients, respectively. ${ }^{(49)}$

A re-evaluation of both $\mathrm{VL}$ and FOB is underway. ${ }^{(2,50)} \mathrm{VL}$ devices now feature in updated difficult airway algorithms, including recommendations that all anaesthetists should be trained and have access to a VL device. ${ }^{(21)}$ Moreover, a recent journal editorial stated that awake FOI is becoming obsolete and is no longer the gold standard for managing the difficult airway. ${ }^{(51)}$ However, acquiring and maintaining FOl skills are important, as attempts at tracheal intubation by $\mathrm{VL}$ devices are not always successful or VL techniques may not be appropriate (e.g. in patients with limited mouth opening).

\section{Skills acquisition}

Although FOI is an essential airway management skill for all anaesthetists, there are substantial variations to the number of times one has to perform it before achieving competence. ${ }^{(52)}$ Opportunities to perform FOI are becoming increasingly limited because of a proliferation of alternative airway equipment such as supraglottic airways ${ }^{(7)}$ and VLs. ${ }^{(2)}$ Skills acquisition can still be achieved through lectures on the principles of airway management as well as hands-on practice in a controlled environment (e.g. bench models, airway workshops with cadavers and specialised bronchoscopic simulators) before proceeding to perform awake or asleep FOI on appropriate patients. ${ }^{.53}$

\section{FOI IN SPECIFIC PATIENT GROUPS Cervical spine injury}

Airway management in patients with unstable cervical spine remains controversial. During direct laryngoscopy, cervical spine movement takes place largely in the occipito-atlantal and atlanto-axial joints, with minimal displacement at the C2-C5 level. ${ }^{(54)}$ Nasal FOI has been shown to produce the least cervical spine displacement in a cadaveric study comparing multiple airway techniques, including face mask ventilation, laryngeal mask airway insertion and direct laryngoscopy. ${ }^{(55)}$ Wong et al also demonstrated reduced cervical spine extension with asleep FOI compared with the LoPro GlideScope ${ }^{(56)}$

Awake FOI for patients undergoing cervical spine surgery seems to be a favoured choice. In one referral centre, it was performed awake in 39\% and asleep in 32\% of such patients; furthermore, awake FOI was the preferred method in cases of unstable or fractured spine (73\%), spinal stenosis (55\%) and myelopathy (45\%). ${ }^{(57)}$ Awake FOI allows the patient to remain in control of his own airway reflexes and to cooperate with a neurological assessment immediately following intubation and positioning, ${ }^{(58,59)}$ but it is not always successful. FOl can fail in patients with unstable upper cervical spine pathology, partly due to a displaced or difficult-to-access larynx secondary to spinal deformity or traction. Maktabi et al described five such cases of failed FOI despite clear visualisation of the vocal cords. Success was achieved when the FOB (without a preloaded tracheal tube) was placed orally to obtain a bird's eye view of the larynx, and a styletted tracheal tube was inserted orally and between the vocal cords under FOB guidance, thereby avoiding impingement and 
laryngeal trauma. ${ }^{(60)}$ In a study by Malcharek et al, awake FOI with mild sedation was performed successfully in 14 patients with cervical instability who were scheduled for cervical surgery in the prone position. ${ }^{(59)} 11$ patients positioned themselves into the prone position, but three failed due to gagging, coughing and feeling uncomfortable about moving into the position. Coughing during awake FOI resulting in secondary cervical spine injury is a theoretical concern in these patients, although there is no strong evidence to support this.

\section{Patients at risk for aspiration}

To minimise the risk of aspiration, which has a mortality of $4 \%$, ${ }^{(61)}$ the airway can be secured while awake or by rapid sequence induction (RSI). An observational study by Ovassapian et al studied 129 awake FOI cases, of which 125 were considered to be at high risk for aspiration of gastric contents. ${ }^{(17)}$ Most were given intravenous sedation. A spray-as-you-go technique of airway topicalisation was applied on 85 occasions and translaryngeal anaesthesia on 29 occasions. One patient had haematemesis, but no other patient had evidence of regurgitation or aspiration. Although having a difficult airway and being at risk of gastric content aspiration are cited as an indication for awake FOI, there is no data in the literature regarding incidence and complications from awake FOI in such patients.

Asleep RSI using FOI was simulated by Pandit et al in anaesthetised patients, including the application of cricoid pressure and rocuronium. ${ }^{(62)}$ They achieved a 93\% success rate on the first attempt at FOI, with a mean intubation time of $111 \pm$ 46 seconds. However, $43 \%$ of patients had one or more (mostly avoidable) difficulties, with $20 \%$ having difficulty in railroading the tracheal tube into the trachea. Another study on RSI using oral asleep FOI showed worse performances in patients with cricoid pressure than without it, the former resulting in more failures (13 vs. 3), and longer mean intubating times (75 [range 43-179] seconds vs. 59 [range 34-144] seconds). ${ }^{(63)}$

Awake rather than asleep FOI is the preferred option in difficult airway patients at risk of aspiration due to the patient maintaining his airway reflexes. The use of VL devices for RSI has the advantage of faster intubation and a reduced likelihood of tube impingement compared to FOI.

\section{Obstetric patients}

The DAS difficult airway algorithm excludes obstetric patients, and there are no specific guidelines on this group in the ASA algorithm. ${ }^{(4,21)}$ New guidelines for the management of difficult and failed intubation in obstetrics were recently published by a joint Obstetric Anaesthetists' Association (OAA) and DAS working party. ${ }^{(64)}$ Difficult and failed intubation occurs in $0.7 \%-4.7 \%$ and $0 \%-0.4 \%$ of the obstetric population, respectively. ${ }^{(65-68)}$ For parturients with anticipated difficult intubation, awake FOI remains an option for securing the airway for surgery. ${ }^{(69)}$ Djabatey and Barclay reported nine patients ${ }^{(66)}$ and McDonnell et al had 64 patients $^{(67)}$ with anticipated difficult intubation. However, awake FOI was only performed in $3(33 \%)$ and $1(2 \%)$ of such cases, respectively. Reasons for the low rate of awake FOI include: alternative options; ${ }^{(70)}$ lack of confidence and skill;; ${ }^{(71)}$ and airway changes in the parturient that make awake FOI more difficult. ${ }^{(72)}$ In emergency cases of unanticipated difficult intubation in the parturient, it would not be feasible to obtain and set up the FOB. In contrast, VL devices are available in $90 \%$ of UK obstetric units and have been used in elective Caesarean section, either as a first-line technique or after failed conventional direct laryngoscopy. ${ }^{(64,73)}$

The recent joint OAA and DAS guidelines recommend that in the event of a failed intubation, a decision should be made whether to proceed with surgery (without tracheal intubation) or to wake the patient. ${ }^{(74)}$ This decision is based on the assessment of multiple factors: maternal and fetal condition; obesity; aspiration risk; surgical factors; and the ability to maintain airway patency and ventilation. If the patient is awakened, then the preferred options are regional anaesthesia or awake intubation. However, there is no specific guidance on the use of $\mathrm{FOI}$ in these updated guidelines. Awake intubation may be via either the FOB or VL device. The oral route is preferred to avoid epistaxis.

\section{Obese patients}

Obesity prevalence is forecast to increase by $33 \%$ over the next two decades, ${ }^{(75)}$ which has grave implications for airway management. In the NAP4 report, there was a twofold and fourfold increase in major airway events for obese and morbidly obese patients, respectively. ${ }^{(7)}$

In the obese population, heterogeneous data gives rise to conflicting results and therefore to a lack of firm recommendations for the management of difficult airways. The incidence of difficult intubation is dependent on which definition is used: $1.9 \%-44.4 \%$ in the super-obese $\left(\mathrm{BMI}>45 \mathrm{~kg} / \mathrm{m}^{2}\right)$ and $3.2 \%-20.4 \%$ in obese (BMI 30-45 kg/m²) patients. ${ }^{(76,77)}$ The 2014 Cochrane review comparing the use of $\mathrm{VL}$ and $\mathrm{FOI}$ for tracheal intubation in obese patients only had three eligible studies with a total of 131 participants. ${ }^{(78)}$ Two of the studies involving asleep FOI showed that it compared unfavourably with other airway devices for first-intubation success $(86.5 \%$ vs. $94.7 \%$ and $0 \%$ vs. $40 \%$, respectively). The review stated that, due to the lack of evidence, it was "unable to draw any conclusion on safety and effectiveness" ${ }^{\prime(78)}$ Recent guidelines by the Association of Anaesthetists of Great Britain and Ireland on the perioperative management of the obese patient did not specify details on the role of awake FOI. ${ }^{(79)}$ However, in the NAP4 report, there were several cases of obese patients in which awake FOI was indicated but not performed. (7) Failure of awake FOI in this subgroup was due to a lack of cooperation, airway obstruction or hypoxia.

The current evidence is inconclusive regarding airway management in obese patients. However, we recommend that if a difficult airway is identified in an obese patient, anaesthetists should not hesitate to perform awake rather than asleep FOI.

\section{Major facial trauma and basal skull fractures}

Major trauma is associated with difficult airways due to: time pressure; presence of blood, secretions, vomitus and foreign 
bodies in the airway; cardiorespiratory compromise; risk of gastric aspiration; facial and cervical spine injuries (requiring inline immobilisation); and brain injuries. Several of these factors may make FOI an inappropriate choice in airway management of major trauma patients. One adult trauma centre (which reported an overall 99.7\% success rate in emergency airway management) did include low-skill FOI (after failed attempts at direct laryngoscopy) and awake FOI in its trauma protocol. ${ }^{(80)}$ Although there was no data regarding the total number of FOI performed in the study, it had two failed awake FOI cases, one of them due to oedema of the airway.

Nasotracheal intubation is considered an absolute contraindication in patients with major facial trauma and/or basal skull fractures due to the risk of direct cerebral injury (via the cribriform plate) and infection (e.g. intracranial, sinusitis, aspiration pneumonia and bacteraemia). ${ }^{(81,82)}$ As conventional nasotracheal intubation is a blind technique through the nasal cavity, performance under direct vision using FOI has a theoretical advantage of avoiding areas of trauma in the nasal airway. Nasal FOI may be considered along with other options for securing the airway, but the clinician must weigh up the respective merits and risks.

\section{Acute airway obstruction}

In cases of predicted or known difficult laryngoscopy, the FOB is ideal for navigating the airway and bypassing oropharyngeal lesions due to the insertion cord's thin diameter and high manoeuvrability. However, in severe acute airway obstruction, its use is contraindicated for several reasons: ${ }^{(37)}$ the patient is not calm or cooperative enough; airway topicalisation and/or sedation may cause loss of airway, including laryngospasm; ${ }^{(32-34)}$ navigation of the FOB is difficult; bleeding or complete obstruction may occur; $^{(28,83)}$ and railroading of the tracheal tube may fail. ${ }^{(28,83)}$ As such, the NAP4 cautioned that "the role of awake FOI is debatable" in these cases. ${ }^{(7)}$ Despite this cautionary statement, one study showed that $90 \%$ of anaesthetists would still choose awake intubation for a patient with laryngeal tumour and stridor undergoing laryngectomy, with $45 \%$ selecting the FOB as the device of choice. ${ }^{(84)}$ In light of the above, we recommend that patients with airway obstruction should be carefully evaluated and alternative forms of securing the airway should be considered.

Few studies have examined the use of flexible FOI in the obstructed airway. Schmitt et al studied 86 patients undergoing awake FOI, who had radiotherapy for carcinoma of the head and neck. They found a $6 \%$ incidence of difficult awake FOI (i.e. vocal cord localisation only with the help of the patient by a deep breathing manoeuvre), and this was strongly associated with the presence of severe laryngeal oedema, stridor and hoarse voice. ${ }^{(85)}$ In another study of 40 head and neck cancer patients with difficult airways, a new type of 'awake fibrecapnic' intubation was used, in which a special suction catheter is inserted into the working channel port of the FOB to detect end-tidal carbon dioxide and act as a guide for railroading the preloaded tracheal tube. ${ }^{(35)}$ All but one case were successfully intubated without complications.

\section{CONCLUSION}

With the development of new airway equipment such as indirect laryngoscopes, flexible FOI is being performed less frequently. ${ }^{(6)}$ However, it still plays a vital role in difficult airway management, as it allows the anaesthetist to have a safe management plan for the anticipated difficult airway and a rescue strategy for the unanticipated difficult airway. Anaesthetists should have a low threshold for using FOI when necessary, and if the decision is made to undertake it, serious consideration should be given to performing it in the awake patient. Awake FOI remains an invaluable choice for airway management in many patients, including those with difficult laryngoscopy (direct and indirect) and cervical spine injuries.

As such, it is vital for the anaesthetist to maintain skill in the use of the flexible, intubating FOB so that it may be used safely and effectively when indicated. Application of theoretical knowledge and practical airway techniques can be achieved via airway workshops, simulation and regular hands-on practice. In current anaesthetic practice, this also involves understanding the role of $\mathrm{FOI}$ alongside a compendium of other airway devices and anaesthetic techniques as part of a complete airway management strategy. The anaesthetist should also be cognisant of the considerations in the use of FOI in special patient groups, exercising caution and prudence in judgement, especially in unanticipated airway emergencies when alternative equipment such as VLs are similarly efficacious and readily available.

\section{REFERENCES}

1. Szmuk P, Ezri T, Evron S, Roth Y, Katz J. A brief history of tracheostomy and tracheal intubation, from the Bronze Age to the Space Age. Intensive Care Med 2008; 34:222-8.

2. Fitzgerald E, Hodzovic I, Smith AF. 'From darkness into light': time to make awake intubation with videolaryngoscopy the primary technique for an anticipated difficult airway? Anaesthesia 2015; 70:387-92.

3. Murphy P. A fibre-optic endoscope used for nasal intubation. Anaesthesia 1967; 22:489-91.

4. Apfelbaum JL, Hagberg CA, Caplan RA, et al; American Society of Anesthesiologists Task Force on Management of the Difficult Airway. Practice guidelines for management of the difficult airway: an updated report by the American Society of Anesthesiologists Task Force on Management of the Difficult Airway. Anesthesiology 2013; 118:251-70

5. Heidegger T, Gerig HJ. Algorithms for management of the difficult airway. Curr Opin Anaesthesiol 2004; 17:483-4.

6. Wanderer JP, Ehrenfeld JM, Sandberg WS, Epstein RH. The changing scope of difficult airway management. Can J Anaesth 2013; 60:1022-4.

7. Royal College of Anaesthetists. 4th National Audit Project of the Royal College of Anaesthetists. Major complications of airway management in the UK. Report and findings, March 2011. Available at: http://www.rcoa.ac.uk/system/files/ CSQ-NAP4-Full.pdf. Accessed July 20, 2016.

8. Lee JS, Wong J, Iqbal R, Wong TG, Wong P. Practical aspects and training in fibreoptic intubation. Trends Anaesth Crit Care 2016; 10:29-41.

9. Sun Y, Liu JX, Jiang H, et al. Cardiovascular responses and airway complications following awake nasal intubation with blind intubation device and fibreoptic bronchoscope: a randomized controlled study. Eur J Anaesthesiol 2010; 27:461-7.

10. Woodall NM, Harwood RJ, Barker GL. Complications of awake fibreoptic intubation without sedation in 200 healthy anaesthetists attending a training course. Br J Anaesth 2008; 100:850-5.

11. Heidegger T, Starzyk L, Villiger CR, et al. Fiberoptic intubation and laryngeal morbidity: a randomized controlled trial. Anesthesiology 2007; 107:585-90.

12. Heidegger T, Gerig HJ, Ulrich B, Schnider TW. Structure and process quality illustrated by fibreoptic intubation: analysis of 1612 cases. Anaesthesia 2003; 58:734-9.

13. Kaneko Y, Nakazawa K, Yokoyama K, et al. Subcutaneous emphysema and pneumomediastinum after translaryngeal intubation: tracheal perforation due to unsuccessful fiberoptic tracheal intubation. J Clin Anesth 2006; 18:135-7. 
14. Hawkyard SJ, Morrison A, Doyle LA, Croton RS, Wake PN. Attenuating the hypertensive response to laryngoscopy and endotracheal intubation using awake fibreoptic intubation. Acta Anaesthesiol Scand 1992; 36:1-4.

15. Xue FS, Zhang GH, Sun HY, et al. Blood pressure and heart rate changes during intubation: a comparison of direct laryngoscopy and a fibreoptic method. Anaesthesia 2006; 61:444-8.

16. Collins SR, Blank RS. Fiberoptic intubation: an overview and update. Respir Care 2014; 59:865-78; discussion 878-80.

17. Ovassapian A, Krejcie TC, Yelich SJ, Dykes MH. Awake fibreoptic intubation in the patient at high risk of aspiration. Br J Anaesth 1989; 62:13-6.

18. Hershey MD, Hannenberg AA. Gastric distention and rupture from oxygen insufflation during fiberoptic intubation. Anesthesiology 1996; 85:1479-80.

19. Ho CM, Yin IW, Tsou KF, Chow LH, Tsai SK. Gastric rupture after awake fibreoptic intubation in a patient with laryngeal carcinoma. Br J Anaesth 2005; 94:856-8

20. Ovassapian A, Mesnick PS. Oxygen insufflation through the fiberscope to assist intubation is not recommended. Anesthesiology 1997; 87:183-4.

21. Frerk C, Mitchell VS, McNarry AF, et al; Difficult Airway Society intubation guidelines working group. Difficult Airway Society 2015 guidelines for management of unanticipated difficult intubation in adults. Br J Anaesth 2015; 115:827-48

22. Sidhu VS, Whitehead EM, Ainsworth QP, Smith M, Calder I. A technique of awake fibreoptic intubation. Experience in patients with cervical spine disease. Anaesthesia 1993; 48:910-3.

23. Du Rand IA, Blaikley J, Booton R, et al; British Thoracic Society Bronchoscopy Guideline Group. British Thoracic Society guideline for diagnostic flexible bronchoscopy in adults: accredited by NICE. Thorax 2013; 68 Suppl 1:i1-i44.

24. Williams KA, Barker GL, Harwood RJ, Woodall NM. Combined nebulization and spray-as-you-go topical local anaesthesia of the airway. Br J Anaesth 2005; 95:549-53.

25. Henderson IJ, Popat MT, Latto IP, Pearce AC; Difficult Airway Society. Difficult Airway Society guidelines for management of the unanticipated difficult intubation. Anaesthesia 2004; 59:675-94.

26. Shiga T, Wajima Z, Inoue T, Sakamoto A. Predicting difficult intubation in apparently normal patients: a meta-analysis of bedside screening test performance. Anesthesiology 2005; 103:429-37.

27. Cook TM, MacDougall-Davis SR. Complications and failure of airway management. Br J Anaesth 2012; 109 Suppl 1:i68-i85.

28. Mason RA, Fielder CP. The obstructed airway in head and neck surgery. Anaesthesia 1999; 54:625-8.

29. Charters P, O'Sullivan E. The 'dedicated airway': a review of the concept and an update of current practice. Anaesthesia 1999; 54:778-86.

30. Frova G, Sorbello M. Algorithms for difficult airway management: a review. Minerva Anestesiol 2009; 75:201-9

31. Cook TM, Morgan PJ, Hersch PE. Equal and opposite expert opinion. Airway obstruction caused by a retrosternal thyroid mass: management and prospective international expert opinion. Anaesthesia 2011; 66:828-36.

32. Ho AM, Chung DC, Karmakar MK, et al. Dynamic airflow limitation after topical anaesthesia of the upper airway. Anaesth Intensive Care 2006; 34:211-5.

33. McGuire G, el-Beheiry H. Complete upper airway obstruction during awake fibreoptic intubation in patients with unstable cervical spine fractures. Can J Anaesth 1999; 46:176-8.

34. Shaw IC, Welchew EA, Harrison BJ, Michael S. Complete airway obstruction during awake fibreoptic intubation. Anaesthesia 1997; 52:582-5.

35. Huitink JM, Balm AJ, Keijzer C, Buitelaar DR. Awake fibrecapnic intubation in head and neck cancer patients with difficult airways: new findings and refinements to the technique. Anaesthesia 2007; 62:214-9.

36. Huitink JM, Buitelaar DR, Schutte PF. Awake fibrecapnic intubation: a nove technique for intubation in head and neck cancer patients with a difficult airway. Anaesthesia 2006; 61:449-52.

37. Wong P, Wong J, Mok MU. Anaesthetic management of acute airway obstruction. Singapore Med J 2016; 57:110-7.

38. Johnston KD, Rai MR. Conscious sedation for awake fibreoptic intubation: a review of the literature. Can J Anaesth 2013; 60:584-99.

39. Bourgain JL, Billard V, Cros AM. Pressure support ventilation during fibreoptic intubation under propofol anaesthesia. Br J Anaesth 2007; 98:136-40.

40. Sørensen MK, Bretlau C, Gätke MR, Sørensen AM, Rasmussen LS. Rapid sequence induction and intubation with rocuronium-sugammadex compared with succinylcholine: a randomized trial. Br J Anaesth 2012; 108:682-9.

41. Wong DT, Mehta A, Tam AD, Yau B, Wong J. A survey of Canadian anesthesiologists' preferences in difficult intubation and "cannot intubate, cannot ventilate" situations. Can J Anaesth 2014; 61:717-26.

42. Cooper RM. Complications associated with the use of the GlideScope videolaryngoscope. Can J Anaesth 2007; 54:54-7.

43. Kramer A, Müller D, Pförtner R, Mohr C, Groeben H. Fibreoptic vs videolaryngoscopic $(\mathrm{C}-\mathrm{MAC}(\mathbb{B}) \mathrm{D}-\mathrm{BLADE})$ nasal awake intubation under local anaesthesia. Anaesthesia 2015; 70:400-6.

44. Moore AR, Schricker T, Court O. Awake videolaryngoscopy-assisted tracheal intubation of the morbidly obese. Anaesthesia 2012; 67:232-5.
45. Rosenstock CV, Thøgersen B, Afshari A, et al. Awake fiberoptic or awake video laryngoscopic tracheal intubation in patients with anticipated difficult airway management: a randomized clinical trial. Anesthesiology 2012; 116:1210-6.

46. Silverton NA, Youngquist ST, Mallin MP, et al. GlideScope versus flexible fiber optic for awake upright laryngoscopy. Ann Emerg Med 2012; 59:159-64.

47. Xue FS, Li CW, Zhang GH, et al. GlideScope-assisted awake fibreoptic intubation: initial experience in 13 patients. Anaesthesia 2006; 61:1014-5.

48. Cormack RS, Lehane J. Difficult tracheal intubation in obstetrics. Anaesthesia 1984; 39:1105-11.

49. Lee MC, Tseng KY, Shen YC, et al. Nasotracheal intubation in patients with limited mouth opening: a comparison between fibreoptic intubation and the Trachway®. Anaesthesia 2016; 71:31-8.

50. Healy DW, Maties O, Hovord D, Kheterpal S. A systematic review of the role of videolaryngoscopy in successful orotracheal intubation. BMC Anesthesiol $2012 ; 12: 32$.

51. Ahmad I, Bailey CR. Time to abandon awake fibreoptic intubation? Anaesthesia $2016 ; 71: 12-6$.

52. de Oliveira Filho GR. The construction of learning curves for basic skills in anesthetic procedures: an application for the cumulative sum method. Anesth Analg 2002; 95:411-6, table of contents.

53. Stringer KR, Bajenov S, Yentis SM. Training in airway management. Anaesthesia 2002; 57:967-83

54. Sawin PD, Todd MM, Traynelis VC, et al. Cervical spine motion with direct laryngoscopy and orotracheal intubation. An in vivo cinefluoroscopic study of subjects without cervical abnormality. Anesthesiology 1996; 85:26-36.

55. Brimacombe J, Keller C, Künzel KH, et al. Cervical spine motion during airway management: a cinefluoroscopic study of the posteriorly destabilized third cervical vertebrae in human cadavers. Anesth Analg 2000; 91:1274-8.

56. Wong DM, Prabhu A, Chakraborty S, et al. Cervical spine motion during flexible bronchoscopy compared with the Lo-Pro GlideScope. Br J Anaesth 2009; 102:424-30.

57. Manninen PH, Jose GB, Lukitto K, Venkatraghavan L, El Beheiry H. Management of the airway in patients undergoing cervical spine surgery. J Neurosurg Anesthesiol 2007; 19:190-4.

58. Langford RA, Leslie K. Awake fibreoptic intubation in neurosurgery. J Clin Neurosci 2009; 16:366-72.

59. Malcharek MJ, Rogos B, Watzlawek S, et al. Awake fiberoptic intubation and self-positioning in patients at risk of secondary cervical injury: a pilot study. J Neurosurg Anesthesiol 2012; 24:217-21.

60. Maktabi MA, Titler SS, Kadakia S, Conway RK. When fiberoptic intubation fails in patients with unstable craniovertebral junctions. Anesth Analg 2009; 108:1937-40.

61. Kluger MT, Short TG. Aspiration during anaesthesia: a review of 133 cases from the Australian Anaesthetic Incident Monitoring Study (AIMS). Anaesthesia 1999; 54:19-26.

62. Pandit JJ, Dravid RM, lyer R, Popat MT. Orotracheal fibreoptic intubation for rapid sequence induction of anaesthesia. Anaesthesia 2002; 57:123-7.

63. Arenkiel B, Smitt M, Olsen KS. The duration of fibre-optic intubation is increased by cricoid pressure. A randomised double-blind study. Acta Anaesthesiol Scand 2013; 57:358-63.

64. Mushambi MC, Kinsella SM, Popat M, et al; Difficult Airway Society. Obstetric Anaesthetists' Association and Difficult Airway Society guidelines for the management of difficult and failed tracheal intubation in obstetrics. Anaesthesia 2015; 70:1286-306

65. Cormack RS. Failed intubation in obstetric anaesthesia. Anaesthesia 2006; 61:505-6; author reply 506 .

66. Djabatey EA, Barclay PM. Difficult and failed intubation in 3430 obstetric general anaesthetics. Anaesthesia 2009; 64:1168-71.

67. McDonnell NJ, Paech MJ, Clavisi OM, Scott KL; ANZCA Trials Group. Difficult and failed intubation in obstetric anaesthesia: an observational study of airway management and complications associated with general anaesthesia for caesarean section. Int J Obstet Anesth 2008; 17:292-7.

68. McKeen DM, George RB, O'Connell CM, et al. Difficult and failed intubation: Incident rates and maternal, obstetrical, and anesthetic predictors. Can J Anaesth $2011 ; 58: 514-24$

69. Preston R, Jee R. Obstetric airway management. Int Anesthesiol Clin 2014; 52:1-28.

70. Kariya N, Kimura K, Iwasaki R, et al. Intraoperative awake tracheal intubation using the Airway Scope ${ }^{\mathrm{TM}}$ in caesarean section. Anaesth Intensive Care 2013; 41:390-2.

71. Popat MT, Srivastava M, Russell R. Awake fibreoptic intubation skills in obstetric patients: a survey of anaesthetists in the Oxford region. Int J Obstet Anesth 2000; 9:78-82.

72. Farcon EL, Kim MH, Marx GF. Changing Mallampati score during labour. Can J Anaesth 1994; 41:50-1.

73. Scott-Brown S, Russell R. Video laryngoscopes and the obstetric airway. Int J Obstet Anesth 2015; 24:137-46.

74. Mushambi MC, Kinsella SM. Obstetric Anaesthetists' Association/Difficult Airway Society difficult and failed tracheal intubation guidelines--the way 
forward for the obstetric airway. Br J Anaesth 2015; 115:815-8.

75. Finkelstein EA, Khavjou OA, Thompson $\mathrm{H}$, et al. Obesity and severe obesity forecasts through 2030. Am J Prev Med 2012; 42:563-70.

76. Dixit A, Kulshrestha M, Mathews JJ, Bhandari M. Are the obese difficult to intubate? Br J Anaesth 2014; 112:770-1.

77. Adnet F, Borron SW, Racine SX, et al. The intubation difficulty scale (IDS): proposal and evaluation of a new score characterizing the complexity of endotracheal intubation. Anesthesiology 1997; 87:1290-7.

78. Nicholson A, Smith AF, Lewis SR, Cook TM. Tracheal intubation with a flexible intubation scope versus other intubation techniques for obese patients requiring general anaesthesia. Cochrane Database Syst Rev 2014; (1):CD010320.

79. Members of the Working Party, Nightingale CE, Margarson MP, et al; Association of Anaesthetists of Great Britain; Ireland Society for Obesity and Bariatric Anaesthesia. Peri-operative management of the obese surgical patient 2015 : Association of Anaesthetists of Great Britain and Ireland Society for Obesity and Bariatric Anaesthesia. Anaesthesia 2015; 70:859-76.

80. Stephens CT, Kahntroff S, Dutton RP. The success of emergency endotracheal intubation in trauma patients: a 10-year experience at a major adult trauma referral center. Anesth Analg 2009; 109:866-72.

81. Hall CE, Shutt LE. Nasotracheal intubation for head and neck surgery. Anaesthesia 2003; 58:249-56.

82. Rosen CL, Wolfe RE, Chew SE, Branney SW, Roe EJ. Blind nasotracheal intubation in the presence of facial trauma. J Emerg Med 1997; 15:141-5.

83. Bonner S, Taylor M. Airway obstruction in head and neck surgery. Anaesthesia 2000; 55:290-1.

84. Jenkins K, Wong DT, Correa R. Management choices for the difficult airway by anesthesiologists in Canada. Can J Anaesth 2002; 49:850-6.

85. Schmitt HJ, Mang H, Schmidt J, Zenk J, Radespiel-Tröger M. Fibreoptic intubation in patients after radiotherapy for carcinoma of the head and neck: difficulty and predictability. Eur J Anaesthesiol 2004; 21:925-7. 